\title{
Relationship between neuropsychiatric signs and symptoms and SARS-CoV-2 infection: a systematic review
}

\author{
Rafaella Moreira ${ }^{1}$, Tahissa Cavalcante ${ }^{1}$, Daniel Damasceno ${ }^{1}$, Raphaella Jansen ${ }^{1}$, José \\ Erivelton Ferreira ${ }^{1}$, and Eloise Barbosa ${ }^{1}$ \\ ${ }^{1}$ UNILAB
}

October 26, 2020

\begin{abstract}
Background: Infection caused by SARS-CoV-2 virus is a recent disease that is easily spread and has serious complications, such as neuropsychiatric signs and symptoms. Thus, studies are necessary on the clinical manifestations during and/or after the course of the disease. Aims and objectives: To describe the relationship between neuropsychiatric signs and symptoms and SARS-CoV-2 infection. Methods: Systematic review conducted in the Pubmed Portal, Brazilian Virtual Health Library, Cochrane, and Science Direct databases. The descriptors coronavirus, SARS, and neurologic symptoms were used in Pubmed, Cochrane, and Science Direct databases, while the descriptors SARS Virus and Nervous System were used in the Virtual Health Library database. A total of 1024 studies were found and 67 were selected to compose this systematic review. The studies were analyzed qualitatively with the narrative description divided into four thematic categories. Results: There is a pathophysiological relationship between SARS-CoV-2 infection and manifestations involving the Central Nervous System and the Peripheral Nervous System through different pathways and mechanisms. The chances of Nervous System manifestations increase in elderly patients with associated morbidities, such as obesity, diabetes mellitus, chronic obstructive pulmonary disease and/or pre-existing neurological/psychiatric diseases. The most cited neuropsychiatric signs and symptoms were headache, delirium, smell and/or taste disorders, and stroke. The evaluation and monitoring of patients during and after COVID19 infection is important for the early detection and treatment of neuropsychiatric signs and symptoms. Conclusions: It is recommended that health professionals monitor patients with COVID-19 infection or who had recently had the disease for detecting neuropsychiatric signs and symptoms, especially elderly patients, people with comorbidities such as cardiovascular and pulmonary diseases, diabetes mellitus, and obesity, and patients with pre-existing neurological/psychiatric diseases. Decisionmaking for the implementation of an early rehabilitation treatment can be reinforced in this groups, minimizing the sequels resulting from COVID-19.
\end{abstract}

\section{Hosted file}

Artigo - Neurological and SARS.pdf available at https://authorea.com/users/370337/ articles/489007-relationship-between-neuropsychiatric-signs-and-symptoms-and-sars-cov-2infection-a-systematic-review

\section{Hosted file}

List Figures.pdf available at https://authorea.com/users/370337/articles/489007-relationshipbetween-neuropsychiatric-signs-and-symptoms-and-sars-cov-2-infection-a-systematic-review

\section{Hosted file}

Tables List.pdf available at https://authorea.com/users/370337/articles/489007-relationshipbetween-neuropsychiatric-signs-and-symptoms-and-sars-cov-2-infection-a-systematic-review 